\title{
Misbalances in Russian agricultural corporations economic growth
}

\author{
Ekaterina Nikolaeva $^{1, *}$, Dmitri Pletnev ${ }^{1}$, and Saeed Mirvahedi ${ }^{2}$ \\ ${ }^{1}$ Chelyabinsk State University, 129, Br.Kashirinykh str., 454001, Chelyabinsk, Russia \\ ${ }^{2}$ Allameh Tabataba'i University, Tehran, Iran
}

\begin{abstract}
The sustainability and balance of companies' growth, especially if they are systemically important for the national economy, is essential for ensuring sustainable development. The article analyzes the balanced growth equilibrium rule for Russian corporations from leading industries: oil and gas industry, transport, metallurgy, and retail. Paper used the data of the official consolidated financial statements for 2011-2019. It is concluded that Russian corporations' growth is not balanced, which can have negative consequences both for their long-term development and for their stakeholders: employees, suppliers, and local communities. In 2019, no corporation demonstrated a balanced growth for key economic indicators. A misbalance in growth is typically observed in two indicators sales revenue and profit on sales. The paper concludes that tendency highlighted leads to weak in investment and other important activities, including sustainable development goal achievement.
\end{abstract}

\section{Introduction}

The strength and stability of economic entities is a necessary condition for national economy sustainable development. This helps companies systematically invest in environmental and environmental projects to develop new investment projects related to the transition to a green economy. One of the critical factors in ensuring the long-term growth and economic strength of corporations is to achieve balanced growth, which manifests itself in the correct ratio of the growth rates of profits, revenues and assets.

While there are dozens of studies on growth, Davidsson, Achtenhagen, \& Naldi [1] observe that there is still much that we do not know. The first contentious issue about business "growth" is its definition. Therefore, a proper first step is to attempt to clarify what growth means. Firstly, growth can be conceptualized in terms of "change in amount" (e.g. size, employees, assets, export, number of products, market share, etc.) and secondly it can connote the "process of development" (Davidsson et al.,[1]; Penrose, [2]) . Extant literature shows that researchers' main emphasis is on the number of changes rather than the process and necessary factors for growth (Davidsson et al. [1]). In other words, it appears that the primary focus of researchers in entrepreneurship is on different measures of growth rather than finding why many entrepreneurial firms grow (Westhead \& Wright [3]). Nevertheless, despite growth heterogeneity and several indicators representing growth

*Corresponding author: nikolaeva@csu.ru 
which are discussed in the literature (Delmar, Davidsson, \& Gartner [4]), the main question is why and how firms grow (D. Brown, Earle, \& Lup, 2005; Hansen \& Hamilton [5]). Firm growth issues are often viewed in the context of the potential for fast growth $[6,7]$ and, ultimately, firms' success [8].

To address this question, we look at several conceptual models in the literature. For example, Storey [9] suggests three main factors: entrepreneur, firm, and strategy. Littunen and Niittykangas [10] found that entrepreneurs' know-how has a very significant impact on growth in the first four years, while in the second period, the business network of entrepreneurs has a clear connection to growth. Hansen and Hamilton [8] observed four main factors in growing firms, which are not present in non-growing firms. These are opportunistic approaches, innovation and flexibility, wide business network, and entrepreneurs' ambition to grow. Dynamic environments can create more significant opportunities for entrepreneurs, and growth is a function of entrepreneurs' motivation and opportunities in the market, especially in niche markets for small firms (Wiklund \& Shepherd [11]).

The article aims to analyze the balance of growth of leading corporations from different sectors of the Russian economy.

\section{Materials and methods}

The study is based on calculating and verifying the following inequality characterizing the balance of growth (balanced growth equilibrium rule, BGER):

$$
\mathrm{T}_{\text {profit }}>\mathrm{T}_{\text {sales }}>\mathrm{T}_{\text {assets }}>100 \%
$$

Failure to meet one of the inequalities indicates an imbalance in corporate growth. Namely:

- non-fulfillment of the first inequality means that profit grows at a lower rate compared to sales; therefore, the company is overrun and inefficient use of resources;

- non-fulfillment of the second part of inequality indicates that additional capital invested in assets leads to a decrease in sales of the corporation, which indicates the inefficiency of its use;

- non-fulfillment of the third part of the inequality indicates the absence of an increase in the company's resource potential, a narrowing of its assets generating sales.

To analyze the level of economic growth of corporations, five largest Russian corporations from various sectors of the economy were selected: PJSC NK Rosneft (oil and gas industry), PJSC Gazprom (oil and gas industry), PJSC Russian Railways (railway transport), PJSC Tander (retail), PJSC MMK (metallurgy). For these corporations, economic growth indicators were determined following the assessment methodology described above, and the implementation of BGER was verified (1).

To test the hypothesis, the following were analyzed: the growth rates of the indicators of the economic activity of corporations according to their consolidated statements for 201119, which make it possible to assess the balance of growth within the BGER - the growth rate of assets, the growth rate of revenue, the growth rate of profit from sales.

In case of non-fulfillment of inequality in one or several indicators, a conclusion is made about growth problem points.

\section{Results}

The study showed different results of BGER (1) testing on these different companies. The analysis of the fulfillment of the above inequality for the PJSC NK Rosneft corporation 
made it possible to conclude that the company had unbalanced growth indicators for almost the entire study period (2010-2019). In 2017 and 2018 alone, BGER met all inequality levels (assets, revenues, profits). Before that, for 4 years, the leading economic indicators' growth rates were not balanced - the revenue growth rate lagged behind the asset growth rate, and the profit growth rate was negative. In 2019, the balance of growth indicators was disturbed by a decrease in the company's revenue for the period (fig. 1).

In the absence of adequate growth in the corporation's revenue (according to BGER) in most periods, investments in asset growth do not give the desired effect in increasing the scale of detail, which is a negative phenomenon of the corporation's development.

In 2017-19, the corporation shown good growth in terms of profit, which indicates an increase in its efficiency. However, until 2017, the rate of profit growth lagged noticeably behind the growth rate of assets and revenue, which was evidence of the low return on the corporation's events.

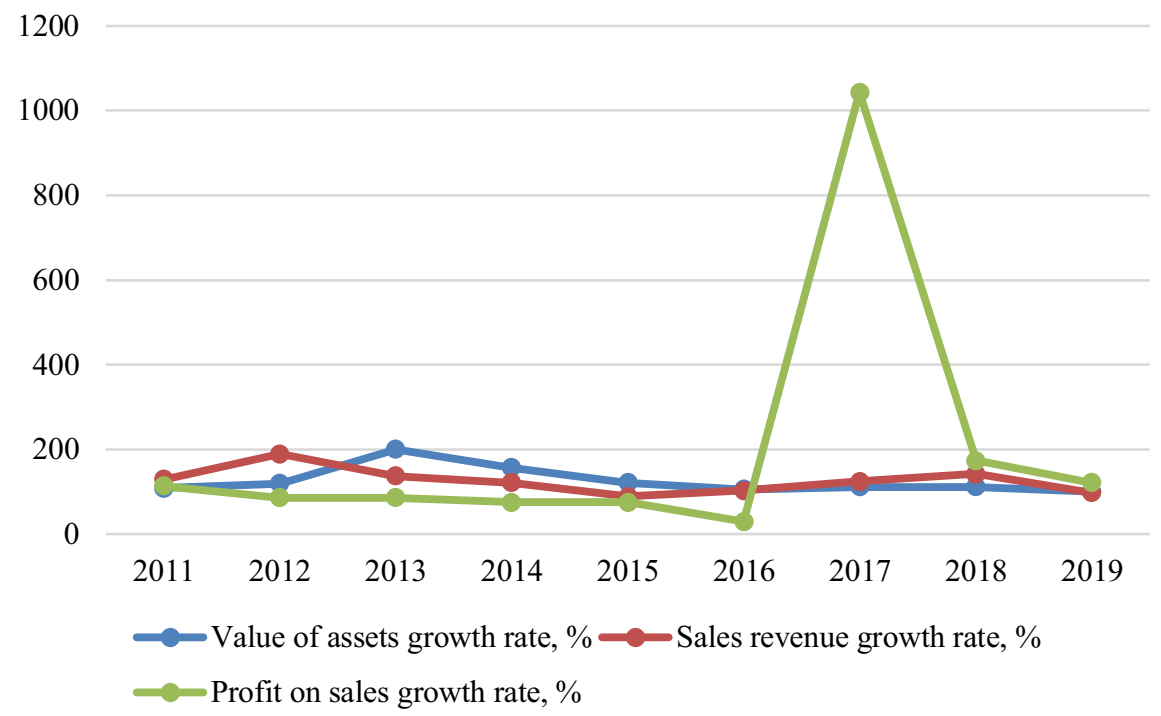

Fig. 1. Balanced growth equilibrium rule checking for NK Rosneft.

In the Gazprom corporation, as in NK Rosneft, the inequality was fulfilled in 2017-2018 (besides this, back in 2011). This gives us grounds to assert that, among other things, sectoral factors also influence the fulfillment of this inequality (fig. 2). In most of the analyzed periods, BGER was not performed in terms of revenue and profit. Here we can also conclude that the return on funds invested in the corporation's assets is low, which was also evident in the last year of the analysis (2019). 


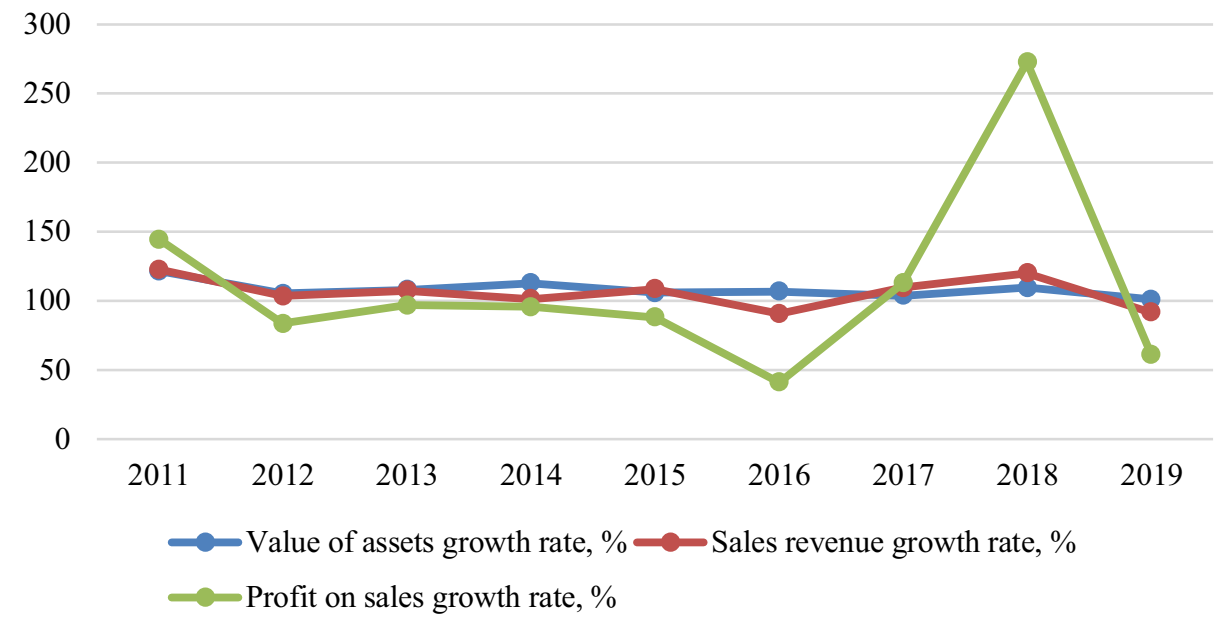

Fig. 2. Balanced growth equilibrium rule checking Gazprom.

In the Russian Railways (RZhD) corporation, BGER has been performed twice over the past 10 years - in 2015 and 2017. Over the years, the company has experienced unbalanced growth in revenue from sales (5 out of 10 periods) and profit from sales (5 out of 10 periods). This also gives grounds to assert that despite the apparent steady growth of all economic activity indicators of Russian Railways PJSC studied in hypothesis 1, this growth was not balanced in terms of cost-benefit, which are manifested in an increase in revenue and profit from sales (fig. 3).

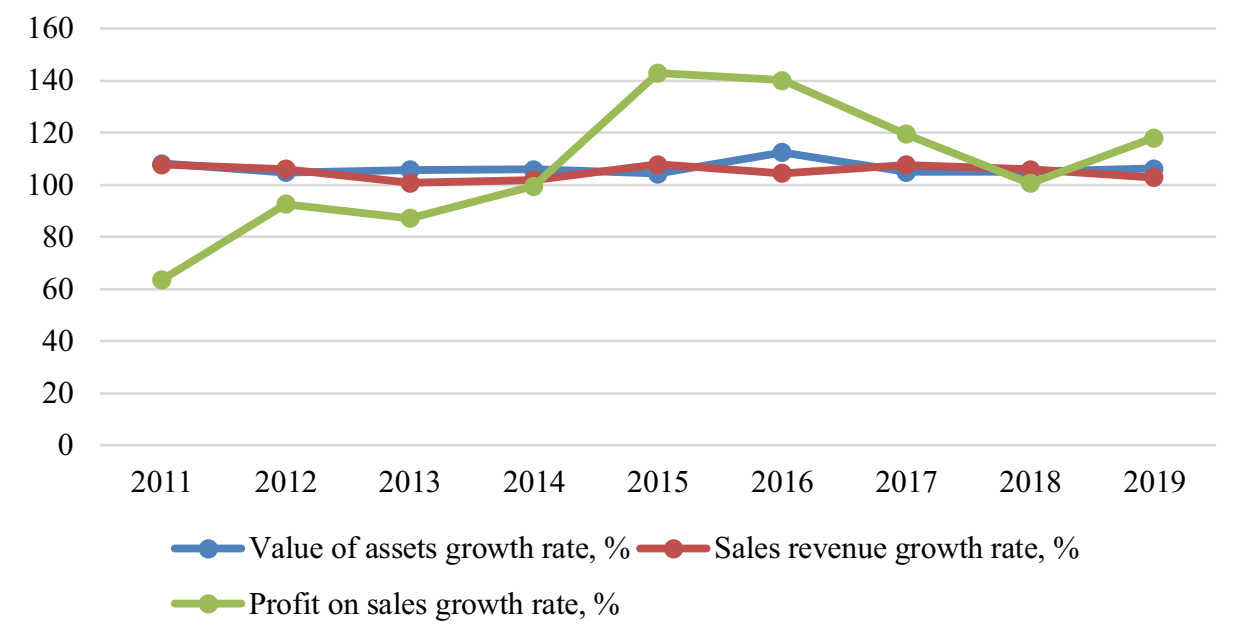

Fig. 3. Balanced growth equilibrium rule checking RZhD.

Balanced growth in economic activity indicators was observed in Tander corporation only in 2012-2013, after which the inequality understudy was not fulfilled even once until 2019. For the most part, BGER is not fulfilled in the corporation in profit from sales growth, which has become negative since 2016. In 2011, 2017 and 2018, the inequality was also not met in terms of sales revenue. Thus, we can conclude that there has been no balanced growth of key indicators of economic activity in Tander corporation in the last 6 years (fig. 4). 


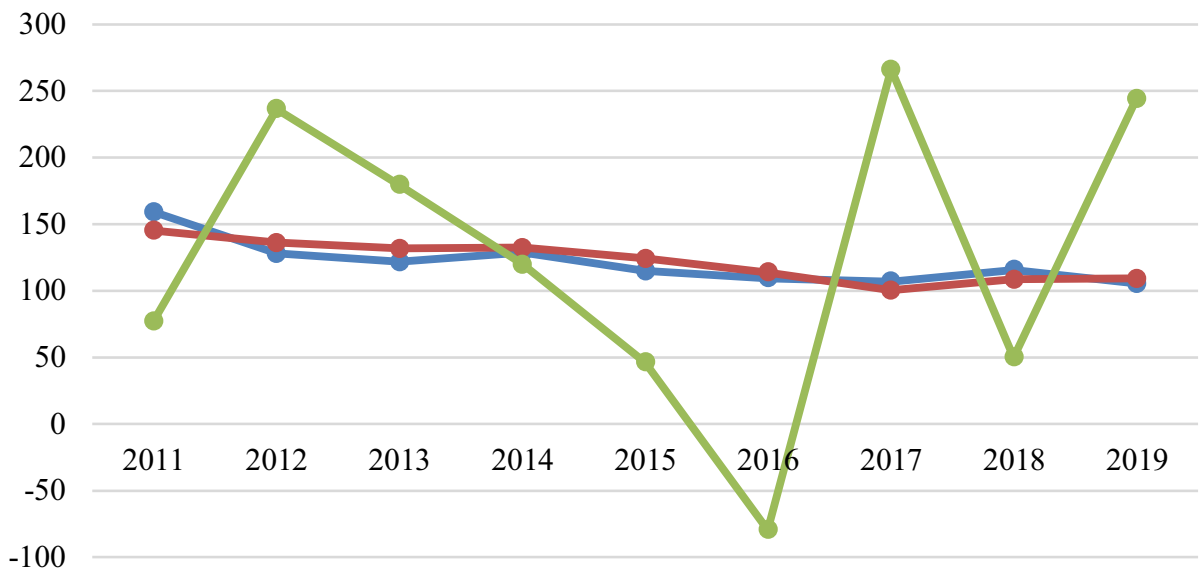

- Value of assets growth rate, $\%-$ Sales revenue growth rate, $\%$

$\longrightarrow$ Profit on sales growth rate, $\%$

Fig. 4. Balanced growth equilibrium rule checking Tander corporation.

The situation with the MMK corporation was slightly better. The verification of the fulfillment of the "golden rule" showed that this inequality was fulfilled only in 2014, 2015 and 2018 - these periods were characterized by a fairly high return on investment in terms of profit (efficiency growth) and moderate returns in terms of sales revenue (growth scale).

A feature of this corporation is that the dynamics of its indicators indicate the failure in certain periods ( 3 out of 10 ) of the inequality under study regarding the growth of the company's assets (fig. 5). This indicates that in these years, the development of the corporation was highly unsatisfactory. Besides, in almost all periods of inequality nonfulfillment, the corporation had gaps with the indicator of profit from sales, proving the lack of efficiency growth from its actions and activities (2011, 2012, 2013, 2017, 2019).

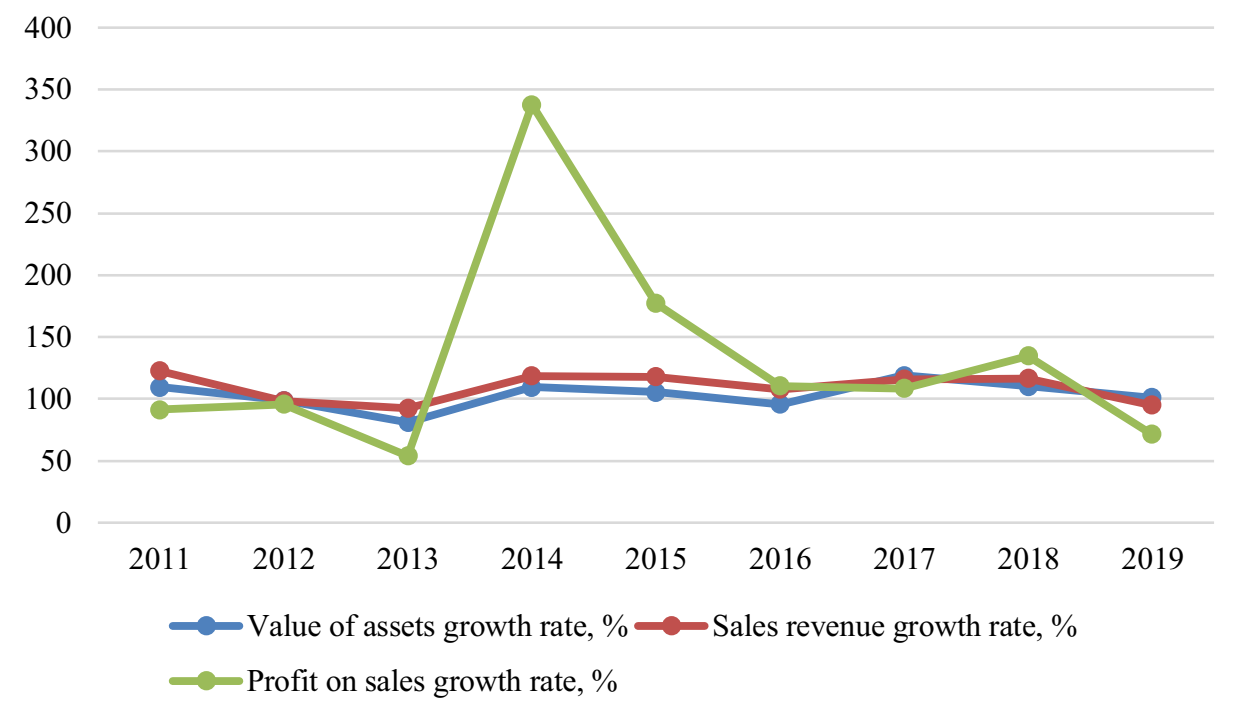

Fig. 5. Balanced growth equilibrium rule checking MMK corporation. 
Generalization and comparative analysis of the results is presented in Table 1.

Table 1. Results of BGER execution in leading Russian corporations.

\begin{tabular}{|c|c|c|c|c|c|c|c|c|c|}
\hline Company & $\mathbf{2 0 1 1}$ & $\mathbf{2 0 1 2}$ & $\mathbf{2 0 1 3}$ & $\mathbf{2 0 1 4}$ & $\mathbf{2 0 1 5}$ & $\mathbf{2 0 1 6}$ & $\mathbf{2 0 1 7}$ & $\mathbf{2 0 1 8}$ & $\mathbf{2 0 1 9}$ \\
\hline Rosneft & $\begin{array}{c}\text { n.h. - } \\
1\end{array}$ & $\begin{array}{c}\text { n.h. - } \\
1\end{array}$ & $\begin{array}{c}\text { n.h. - } \\
1,2\end{array}$ & $\begin{array}{c}\text { n.h. - } \\
1,2\end{array}$ & $\begin{array}{c}\text { n.h. - } \\
1,2\end{array}$ & $\begin{array}{c}\text { n.h. - } \\
1,2\end{array}$ & h. & h. & $\begin{array}{c}\text { n.h. - } \\
2\end{array}$ \\
\hline Gazprom & h. & $\begin{array}{c}\text { n.h. - } \\
1,2\end{array}$ & $\begin{array}{c}\text { n.h. - } \\
1,2\end{array}$ & $\begin{array}{c}\text { n.h. - } \\
1,2\end{array}$ & $\begin{array}{c}\text { n.h. - } \\
1\end{array}$ & $\begin{array}{c}\text { n.h. - } \\
1,2\end{array}$ & h. & h. & $\begin{array}{c}\text { n.h. - } \\
1,2\end{array}$ \\
\hline RZhD & $\begin{array}{c}\text { n.h. - } \\
1,2\end{array}$ & $\begin{array}{c}\text { n.h. - } \\
1\end{array}$ & $\begin{array}{c}\text { n.h. - } \\
1,2\end{array}$ & $\begin{array}{c}\text { n.h. - } \\
1,2\end{array}$ & h. & $\begin{array}{c}\text { n.h. - } \\
2\end{array}$ & h. & $\begin{array}{c}\text { n.h. } \\
-1\end{array}$ & $\begin{array}{c}\text { n.h. - } \\
2\end{array}$ \\
\hline Tander & $\begin{array}{c}\text { n.h. - } \\
1,2\end{array}$ & h. & h. & $\begin{array}{c}\text { n.h. - } \\
1\end{array}$ & $\begin{array}{c}\text { n.h. - } \\
1\end{array}$ & $\begin{array}{c}\text { n.h. - } \\
1\end{array}$ & $\begin{array}{c}\text { n.h. }- \\
1,2\end{array}$ & $\begin{array}{c}\text { n.h. } \\
-1,2\end{array}$ & $\begin{array}{c}\text { n.h. - } \\
1\end{array}$ \\
\hline MMK & $\begin{array}{c}\text { n.h. - } \\
1\end{array}$ & $\begin{array}{c}\text { n.h. - } \\
1,2,3\end{array}$ & $\begin{array}{c}\text { n.h. - } \\
1,3\end{array}$ & h. & h. & $\begin{array}{c}\text { n.h. - } \\
3\end{array}$ & $\begin{array}{c}\text { n.h. - } \\
1,2\end{array}$ & h. & $\begin{array}{c}\text { n.h. - } \\
1,2\end{array}$ \\
\hline
\end{tabular}

h. -BGER inequality holds;

n.h. -BGER inequality not holds, namely:

1 - by the of profit on sales;

2 - by the sales revenue;

3 - by the value of the asset.

\section{Conclusion}

The analysis made it possible to draw several conclusions regarding the balanced growth of Russian corporations. First, the balanced growth equilibrium rule was fulfilled in the studied corporations in rare cases (no more than three times in ten years for each of the corporations), which allows us to speak in general about the imbalance of growth in these companies. Second, in 2016 and 2019, no corporation demonstrated a balanced growth for key economic indicators. Third, a misbalance in growth is observed in corporations in two indicators - sales revenue and profit on sales. It indicates a weak return on investments in companies' assets, both in terms of expanding the scale of their activities and, significantly, in part of the increase in ongoing activities' effectiveness.

\section{References}

1. P. Davidsson, L. Achtenhagen, L. Naldi, Research on small firm growth: A review (European Institute of Small Business, Brisbane, Australia, 2005)

2. E.T. Penrose, The theory of the growth of the firm (Oxford University Press, Oxford, 1995)

3. P. Westhead, M. Wright, International Small Business Journal 29(6), 714-729 (2011) doi: $10.1177 / 0266242611424552$

4. F. Delmar, P. Davidsson, W.B. Gartner, Journal of business venturing 18(2), 189-216 (2003) doi:10.1016/s0883-9026(02)00080-0

5. D. Brown, J.S. Earle, D. Lup, Economic Development and Cultural Change 54(1), 3370 (2005) doi:10.1086/431264

6. D. Pletnev, K. Naumova, S. Mirvahedi, E3S Web of Conferences 04029, 157 (2020) doi:10.1051/e3sconf/202015704029

7. D. Pletnev, V. Barkhatov Innovation in Sustainable Management and Entrepreneurship. SIM 2019. Springer Proceedings in Business and Economics. Springer, Cham, 127-136 (2020) https://doi.org/10.1007/978-3-030-44711-3_10 
8. D. Pletnev, E. Nikolaeva, Advances in Intelligent Systems and Computing. Springer, Cham 1116, 643-656 (2020) https://doi.org/10.1007/978-3-030-37919-3_65

9. D.J. Storey, Understanding the small business sector (Routledge, New York, 1994)

10. H. Littunen, H. Niittykangas, Journal of Small Business and Enterprise Development 17(1), 8-31 (2010) doi:10.1108/14626001011019107

11. J. Wiklund, D. Shepherd, Journal of Management Studies 40(8), 1919-1941 (2003) doi:10.1046/j.1467-6486.2003.00406.x 